\title{
Elementos de política de indexação em biblioteca universitária da área médica
}

Elementos de política de indización para bibliotecas universitarias del área médica

Elements of indexing policy for medical academic libraries

\section{Franciele Marques Redigolo (1), Roberta Cristina DAL'Evedove (2), Mariângela Spotti Lopes FuJITA (3), Vera Regina Casari Boccato (4)}

$(1,3)$ Universidade Estadual Paulista, Av. Hygino Muzzi Filho, 737, Campus Universitário, CEP. 17525900, Marília, SP, Brasil, Caixa-Postal: 421 (1) francieleredigolo@gmail.com (3) fujita@marilia.unesp.br (2, 4) Universidade Federal de São Carlos, Rodovia Washington Luís, km 235, SP-310. CEP 13565-905, São Carlos, SP, Brasil (2) roberta_tartarotti@yahoo.com.br (4) vboccato@ufscar.br

\begin{abstract}
Resumen
En el contexto de las bibliotecas universitarias, la optimización de servicios, los procesos de racionalización y coherencia de la elaboración y organización de los contenidos informativos están fuertemente influenciados por la política de indexación aprobada por el sistema de información. En este artículo se ha propuesto llevar a cabo una investigación teóricametodológica sobre la indización por materias con el fin de contribuir a la definición de elementos de política de indización en biblioteca universitaria del área médica, con estudios prácticos en torno a los elementos de la política de indexación. Para lograr nuestro objetivo, hemos aplicado tres instrumentos: análisis de la cultura organizacional, protocolo verbal individual y evaluación de la indización. Se considera la importancia de desarrollar una política de indización de mejoras en los procesos y servicios ofrecidos por las bibliotecas universitarias, así como la recuperación de la información de la comunidad de usuarios. Es necesario realizar más estudios con catalogadores, expertos, usuarios y gestores del campo de la medicina para mejorar el manual de indización.
\end{abstract}

Palabras clave: Indización. Política de indización. Cultura organizacional. Protocolo verbal. Evaluación de la indización. Bibliotecas universitarias. Medicina.

\section{Introdução}

$\mathrm{Na}$ literatura e na prática, poucos são os esforços voltados à elaboração de política de indexação em bibliotecas universitárias e, de acordo com Nunes (2004) geralmente as bibliotecas não dedicam tempo a esta temática.

Ressalta-se ainda a influência dos recursos aos quais a biblioteca tem acesso, sendo ou não possível dispor em seu quadro de bibliotecários um número suficiente de profissionais, para que possam ocupar-se da política de indexação quando há o desenvolvimento da indexação na instituição.

\begin{abstract}
In the context of university libraries, the optimization and streamlining of services and processes related to informational content indexing and retrieval are strongly influenced by the indexing policy adopted. This article is aimed at researching the indexing policy elements that are more suitable for medical university libraries. To achieve our objective, we applied three instruments: organizational culture analysis, individual verbal protocol and evaluation of indexing. Results emphasize the importance of developing an indexing policy to improve the processes and services offered by university libraries, as well as the retrieval of information by the user community. More studies are necessary in the medical area involvoving catalogers, experts, users and managers for the development of the indexing manual.
\end{abstract}

Keywords: Indexing. Indexing policy. Organizational culture. Verbal protocol. Assesment. University libraries. Medicine.

Destacam-se pesquisas como Guimarães (2004) e Rubi $(2004,2008)$ que apontam a importância do desenvolvimento de política de indexação para o estabelecimento de coordenadas e diretrizes sobre o processo de indexação, principalmente em bibliotecas universitárias e especializadas.

Deste modo, uma política de indexação, definida por Carneiro (1985), é um guia de tomada de decisões. No entanto, apesar de sua relevância, as bibliotecas em sua grande maioria não estabelecem a construção de uma política e quando as têm, percebe-se uma demora no tempo de atualização. 
Uma política de indexação bem elaborada, com diretrizes pensadas de acordo com o contexto da instituição e com as necessidades dos usuários, propicia o desenvolvimento da indexação com maior rigor, buscando mais consistência e a qualidade da indexação.

Esta discussão propôs realizar uma investigação sobre a catalogação de assunto visando a contribuir com estudo para a definição de elementos de política de indexação em biblioteca universitária da área médica, apresentando estudo exploratório em busca de contribuições para esta área.

Deste modo, a pesquisa discute subsídios sobre o contexto da catalogação de assunto, no intuito de compreender como a atividade vem sendo realizada pelo catalogador na área de Medicina, além de analisar a cultura organizacional e avaliar a consistência da indexação, visando à elaboração de diretrizes para uma política de indexação em contexto de bibliotecas universitárias.

\section{Política de indexação}

Considerando-se a relevância da indexação e da catalogação de assunto, desenvolvidas basicamente com a análise e leitura do documento, identificação e seleção de conceitos, Chaumier (1988), Dias e Naves (2007), Fujita (2003) e Lancaster (2004), dentre outros, discorrem que a qualidade da análise de assunto é o que condiciona valor a um sistema informacional.

Segundo Fujita (2001), a análise de assunto é uma etapa do processo de indexação e possui um alto nível de relevância, pois deverá resultar na representação do assunto principal do documento.

Ademais, sobre a representação documental, na visão de Kobashi (1994, p. 17), são atividades que não são neutras e, afirma que:

a política dos sistemas documentários afetam cada uma das operações praticadas em seu interior, desde aquelas relacionadas à seleção de documentos até as que dizem respeito aos produtos a serem gerados.

Além disso, para Gil Leiva $(2002,2008)$ na indexação de um documento existem diversas variáveis, como a formação do profissional que analisa o documento e sua experiência em indexação; o domínio das ferramentas empregadas na indexação, no caso de sua utilização; o conhecimento do âmbito temático em que se insere o documento e as diretrizes de Indexação do contexto onde o profissional atua.

Os fatores que podem influir e condicionar a consistência da indexação também foram anali- sadas em seu conjunto por Lancaster (1991), analisadas e discutidas também por Fujita (2003), e Moreno Fernández (2003) elabora um estudo sobre a relação entre os fatores e variáveis que influenciam na indexação com a coerência e a qualidade da indexação.

Justifica-se e intensifica, também, a importância da elaboração de uma política de indexação que dê diretrizes para esta atividade, visando a meIhorias nos processos e serviços oferecidos pela biblioteca universitária, assim como a recuperação da informação por parte da comunidade usuária.

Por política de indexação, Gil Leiva (2008) a define como a forma de realizar a indexação de uma determinada instituição como o esforço por concretizar, sistematizar e reunir em manuais os processos da indexação. E ainda que esta reunião dos procedimentos em manuais esteja diretamente relacionada com o número de profissionais que se dedicam a esta atividade de indexação e ao nível de qualidade que o sistema de informação pretende alcançar.

Assim, os manuais de indexação são importantes não apenas para a formação de novos indexadores como também para a formação contínua de indexadores experientes.

Vistas estas considerações, constata-se que a política de indexação está inserida em dois contextos complementares: o contexto sociocognitivo do profissional - a política de indexação, as regras e os procedimentos do manual de indexação, a linguagem documental para representação e mediação da linguagem natural do usuário e seus interesses de busca; e o contexto físico de trabalho (Fujita, 2003).

Na visão de Cesarino e Pinto (1978), a política de indexação consiste em uma decisão gerencial tradicional, que divide as atividades informativas em gerenciais, de processamento e de interface com o usuário, passando a ver a gestão da unidade ou serviço de informação como um todo, no qual se inserem atividades de organização, disponibilização e uso da informação, de forma integrada e interdependente.

A implementação de uma política de indexação pressupõe dois aspectos fundamentais: a interdependência de seus elementos e a avaliação constante, visto que é um processo retroalimentável por natureza (mudam os documentos, as áreas de interesse da organização, os perfis dos usuários, as linguagens de indexação, etc.).

A política de indexação influencia em questões como a otimização de serviços, a racionalização de processos e a consistência das operações 
de tratamento e organização de conteúdos informacionais.

Assim, passa a assumir papel preponderante como modalizador das interações no intuito de levar o usuário à delimitação dos objetivos, interesses e níveis de extensão que pretende com a busca da informação e também de complementar o trabalho de organização do documento no sistema de recuperação da informação de qualquer biblioteca.

Guimarães (2000) adverte que o estabelecimento de uma política de indexação contribuirá, também, para que usuário e documento tornemse elementos passíveis de interação, uma vez que o usuário estará sempre recriando o documento e, por consequência, alimentando novamente o sistema.

\section{Metodologia}

A pesquisa caracteriza-se como uma pesquisa exploratória qualitativa-quantitativa. Para o desenvolvimento desta investigação foram aplicados três métodos: Cultura Organizacional, Protocolo Verbal Individual e Avaliações Intrínseca e Extrínseca.

A partir da cultura organizacional, foi possível levantar toda a infraestrutura pertencente ao âmbito de trabalho do catalogador, bem como os tipos de ferramentas disponíveis, o acervo que a biblioteca possui e o grupo de usuários mais frequentes na Biblioteca da Faculdade de Ciências Médicas (BFCM) (Bibliotecas da UNICAMP, SBU). O questionário foi utilizado com o objetivo de complementar os dados referentes ao contexto a ser analisado, bem como a história do núcleo básico da Biblioteca.

O protocolo verbal individual proporcionou a observação da realidade profissional e também a discussão de alguns elementos que envolvem a política de indexação, como a quantidade de termos para a determinação de assunto, o uso de linguagem documental, atualização dos termos de indexação, explicitação dos objetivos de leitura e também o uso da política de indexação durante a catalogação.

A avaliação intrínseca foi aplicada a esta investigação por meio da fórmula de Hooper (1965), adaptada por Gil Leiva (2008), a fim de medir a consistência da catalogação realizada na instituição pesquisada com mais cinco instituições nacionais e internacionais.

Por sua vez, a avaliação extrínseca foi utilizada com o propósito de comparar o resultado da determinação do assunto na catalogação entre outras catalogações do mesmo livro entre diferentes bibliotecas.

\subsection{Cultura Organizacional}

O processo de indexação deve refletir a cultura organizacional de uma biblioteca, a qual insere o sistema de informação representado por seus elementos culturais.

Portanto, se o objetivo da indexação é dar acesso aos documentos e tornar disponível a informação para posterior recuperação, o ambiente cultural predominante do catalogador pode garantir a qualidade na recuperação da informação pelo usuário.

Cada biblioteca possui seu caráter organizacional e sofre influências da cultura da organização que a engloba, sendo expressa pela maneira como se trata os usuários, pelo ambiente físico, pelo grau de lealdade expresso aos funcionários, entre outros (Boccato e Fujita, 2005).

Com o intuito de levantar aspectos que envolvem a cultura organizacional referentes ao contexto físico da Biblioteca e a infraestrutura em que o catalogador está inserido, utilizou-se os questionamentos elaborados por Rubi (2004):

1. Qual a área física da Biblioteca?

2. Recursos materiais

2.1. Quais os equipamentos, sejam para os usuários ou para a equipe da Biblioteca disponíveis? (computador, scanner, retroprojetor, leitor de microfichas, etc.). Especifique a quantidade de cada tipo.

2.2. Qual a quantidade de livros, títulos de periódicos, teses existentes?

3. Quantos funcionários trabalham na Biblioteca? Especifique suas respectivas funções. Inclua, se possível, o organograma administrativo.

\section{Usuários}

4.1. Quantos usuários internos são atendidos?

4.2. Quantos usuários externos são atendidos?

5. Quais os serviços executados?

\subsection{Protocolo Verbal Individual}

O Protocolo Verbal Individual, ou PVI, vem sendo adotado para estudos de observação em leitura, compreensão de metáforas, interpretação de poesias, auxílio no ensino de língua estrangeira e como instrumento pedagógico para o ensino em sala de aula (Fujita e Rubi, 2007). Nesta modalidade de protocolo, o pesquisador não pode interagir com o sujeito, questionando-o ou direcionando-o de acordo com os interesses de pesquisa. Apenas deve lembrar o sujeito que ele deve exteriorizar os seus pensamentos durante a atividade. 
O pesquisador deve também, controlar o apareIho gravador e fazer anotações pertinentes aos objetivos da pesquisa (Fujita e Rubi, 2007). Seguem-se os procedimentos adotados para a coleta de dados:

- Procedimentos anteriores à coleta de dados:

- Definição do universo da pesquisa: Catalogador da área de Medicina.

- Seleção do Texto-Base: Wilkins, Robert L., Stoller, James K., Karcmarek, Robert M. Egan fundamentos da terapia respiratória. 9.ed. Rio de Janeiro: Mosby/Elsevier, 2009. 1386 p.

- Definição da tarefa: Coleta do PVI, durante a catalogação de um livro da área de Medicina, que consiste na gravação de voz enquanto o profissional realiza a atividade.

- Seleção dos Sujeitos: Catalogador da Diretoria de Tratamento da Informação da UNICAMP (DTRI).

- Conversa informal com os sujeitos: Para explicitar os objetivos da coleta.

—Familiarização com a tarefa do "Think Aloud": Familiarização com a tarefa de "Pensar Alto".

- Procedimentos durante a coleta de dados:

- Gravação do "Pensar Alto" durante a leitura do texto-base: Os sujeitos devem exteriorizar os seus pensamentos e realizarem a leitura do material em voz alta

- Entrevista retrospectiva (optativa): Podem ser realizadas algumas questões para sanar dúvidas.

- Procedimentos posteriores à coleta de dados:

- Transcrição literal das gravações das falas dos sujeitos (Protocolo Verbal Individual): A transcrição deu-se de maneira a destacar a compreensão do sujeito (Catalogador).

- Leitura detalhada dos dados em busca de fenômenos significativos e recorrentes para construir categorias de análise.

- Construção das categorias de análise: Ver as categorias de análise.

- Retorno aos dados para retirar trechos da discussão que exemplificassem cada fenômeno, cada categoria.

Por meio das categorias de análise foi possível levantar aspectos para análise referentes a alguns tópicos que precisam ser considerados para o estudo de elaboração de uma política de indexação (ver categorias no capítulo de resultados).

3.3. Avaliações: avaliação extrínseca mediante a interconsistência e a avaliação intrínseca quantitativa

A avaliação da indexação é importante para medir e avaliar os aspectos intrínsecos e extrínsecos da indexação. De acordo com a literatura, os resultados do processo de catalogação de assunto em bibliotecas universitárias podem ser obtidos por meio de avaliações extrínsecas e intrínsecas.

A Avaliação Intrínseca está relacionada com o resultado da Indexação, com a finalidade de conhecer a sua qualidade. Este tipo de avaliação pode ser qualitativa ou quantitativa (Gil Leiva, 2008).

A avaliação extrínseca, no entanto, serve para medir o resultado da Indexação para compará-lo com a indexação de outra unidade de informação que também tenha indexado o mesmo documento. Este tipo de avaliação pode ser mediante a interconsistência e também pela recuperação (Gil Leiva, 2008). Para Gil Leiva (2008), uma comparação entre indexações deve começar por um estudo prévio dos fatores das instituições (fatores ligados ao catalogador; fatores relacionados ao contexto; fatores ligados ao objeto). A Avaliação Extrínseca Mediante a Interconsistência, segundo Gil Leiva (2008), é um tipo de avaliação de indexação que tem como objetivo medir o resultado da indexação para compará-lo com a indexação de outras bibliotecas que também indexaram o mesmo livro. A Avaliação Intrínseca Quantitativa, segundo Gil Leiva (2008, p. 386), refere-se ao uma reindexação de um conjunto de documentos repetindo-se, na medida do possível, as condições nas quais foi produzida a primeira Indexação, para conseguir índices de consistência entre duas indexações por meio de fórmulas matemáticas.

Portanto, para esta investigação, a fórmula de Hooper (1965), adaptada por Gil Leiva (2008), foi aplicada aos resultados das catalogações originais de suas instituições. A Fórmula da consistência adaptada de Hooper (1965) por Gil Leiva (2008, p. 386), apresenta-se na seguinte conformidade:

\footnotetext{
$\mathrm{Ci}=\mathrm{Tco} /[(\mathrm{A}+\mathrm{B})-\mathrm{Tco}]$

Tco = Número de termos comuns nas duas indexações

$A=$ Número de termos usados na indexação $A$

$B=$ Número de termos usados na indexação $B$

$\mathrm{Ci}=$ Índice de Consistência
} 


\section{Resultados}

\subsection{Cultura Organizacional:} a identificação da organização

A biblioteca que comporta o sistema de indexação escolhido como amostra para esta pesquisa é a Biblioteca da Faculdade de Ciências Médicas (BFCM) da Universidade Estadual de Campinas. Ao total, 27 Bibliotecas seccionais compõem o Sistema de Bibliotecas da UNICAMP.

A organização que está vinculada ao sistema de informação selecionado para este estudo é uma Universidade (UNICAMP) que oferece cursos de graduação e pós-graduação em diferentes áreas do conhecimento (Biológicas e Profissões de Saúde, Artes, Humanas, Exatas, Tecnológicas e da Terra), apoiando-se no tripé pesquisa, ensino e extensão. A Coordenação do Sistema de Bibliotecas da Unicamp está fisicamente localizada na Biblioteca Central "Cesar Lattes" (BCCL). O acervo das Bibliotecas é formado principalmente por livros, periódicos e dissertações/teses nas áreas de Artes, Biomédicas, Exatas, Humanidades e Tecnológicas. Este sistema possibilita o acesso à informação gerada pela Universidade e pela comunidade científica do país e do exterior e o acesso e consulta ao material catalogado são livres e abertos ao público em geral, porém empréstimos são realizados apenas à comunidade da UNICAMP.

\subsubsection{A identificação da clientela} a que se destina o sistema (destinatário)

A Biblioteca da Faculdade de Ciências Médicas (BFCM) é destinada principalmente a atender aos discentes, docentes e à comunidade da Faculdade de Ciências Médicas da UNICAMP, que oferta os cursos de graduação em Medicina, Enfermagem, Fonoaudiologia e Farmácia. Os cursos de pós-graduação oferecidos também abrangem a área médica. Ao total, a Biblioteca possui cerca de 5.000 usuários ativos.

\subsubsection{Os recursos humanos,} materiais e financeiros (infraestrutura)

O quadro de colaboradores que compõe a equipe de recursos humanos da Biblioteca da Faculdade de Ciências Médicas (BFCM) é composto por 24 colaboradores no total: funcionários, 12; diretora bibliotecária, 1; bibliotecárias, 2; técnico, 3; técnico administrativo, 2; estagiários, 2; bolsista, 1; e patrulheira, 1.

O acervo é composto por: Livros $=8.919$, Títulos de Periódicos $=1.116$, Teses $=4.937$. $\mathrm{A}$ área física total da Biblioteca é de 1.200 metros, sendo o prédio dividido em dois andares.
No entanto, outro ponto que se observa nesta biblioteca é a abrangência e diversificação das áreas de conhecimento coberta pelos acervos das Bibliotecas. Ao total, são 25 Bibliotecas com acervos diversificados e necessidades variadas de diferentes usuários. Uma única política de indexação para abranger a todas as Bibliotecas do sistema tornar-se-ia insuficiente. Uma solução seria formar comissões de Bibliotecários de cada área de conhecimento/biblioteca que os acervos da Biblioteca da Unicamp abrangem, a fim de formar políticas de indexação para cada área. Com isso, o modelo de Leitura Documentária proposto por Fujita (2003) e a própria NBR 12.676 poderiam trazer contribuições significativas.

Sabe-se que o processo de indexação é imbuído de subjetividade e cabe aos profissionais Bibliotecários construírem Políticas de Indexação que os orientem e os direcionem no seu fazer cotidiano.

\subsection{Processo de indexação desenvolvido pelo catalogador em Biblioteca Universitária}

Os procedimentos e alguns esclarecimentos que foram utilizados pelo catalogador possibilitaram a verificação de como determinou o assunto e quais são as participações da política de indexação/manual nesta instituição. As categorias de análise envolveram algumas características que uma política de indexação deve englobar, assegurando a melhor e mais eficaz representação da informação.

As categorias foram extraídas das estratégias metacognitivas de leitura de Brown (1980), da norma ABNT (1992) e também foram elaboradas a partir da leitura da transcrição do protocolo verbal, extraindo conceitos que o próprio catalogador expôs durante a catalogação: exame do documento de acordo com a norma 12.676 (ABNT, 1992) e alocamento de atenção a áreas importantes (Brown, 1980, apud Redigolo, 2010); explicitação dos objetivos da leitura (Brown, 1980); preocupação com o interesse de pesquisa dos usuários; definição da quantidade de termos na catalogação de assunto; uso e importância de uma política de indexação ou manual; uso de linguagem documentária; e atualização dos termos inseridos na base Acervus.

\subsubsection{Exame do documento de acordo com a norma 12.676}

Nas categorias baseadas nas estratégias metacognitivas desenvolvidas por Brown (1980) utilizadas para a análise deste Protocolo Verbal Individual (PVI) que foram: Alocamento de aten- 
ção a áreas importantes e Explicitação dos objetivos da leitura (Brown, 1980) refletem as estratégias durante a Leitura Documentária a fim de que seu objetivo seja atingido: identificação e extração dos conceitos do documento. As estratégias são ações realizadas pelo leitor no ato da leitura, no caso da leitura profissional, geralmente direcionadas para a solução de um problema (Redigolo, 2010).

Durante a indexação, os conceitos são extraídos do documento através de uma análise, e são traduzidos para os termos de instrumentos de indexação. Dessa forma, a identificação dos conceitos envolve como aspecto principal a compreensão do conteúdo do documento pelo leitor, de forma a representar e propiciar a seleção dos conceitos válidos para recuperação (Dal' Evedove, 2002).

Portanto, no momento da leitura exige-se do leitor-indexador conhecimentos para que haja uma compreensão do significado do texto e de seu conteúdo. Para Borba (2003) o conhecimento prévio é um elemento que se intitula essencial para o leitor durante o processo de leitura para que haja a sua compreensão.

Segundo Dal' Evedove (2002), a compreensão de leitura do indexador humano no processo de análise é importante para uma análise conceitual que represente adequadamente o conteúdo do documento a ser indexado.

Mais forte do que a falta de conhecimento prévio específico, é a concepção de análise assumida pelo indexador ao realizar a análise de um texto com fins de indexação, considerando-se as diferentes concepções de análise de assunto que afetam o desempenho do indexador enquanto leitor: concepção simplista, orientada para o conteúdo e orientada para a demanda.

A análise nesta categoria compreende as partes textuais que o Catalogador percorreu para identificar os conceitos contidos no documento. Verifica-se que o Catalogador apenas prendeu-se ao título e ao sumário propostos pela Norma 12.676 (ABNT, 1992), bem como à ficha catalográfica do livro. Todavia, é oportuno destacar que a referida norma não identifica quais são os tipos de conceitos que podem ser encontrados em cada parte textual indicada.

No entanto, percebe-se que o profissional não segue uma sistemática para análise dos documentos, pois analisou o conteúdo do documento apenas quando já tinha identificado os termos nas partes textuais citadas acima.

Tais categorias também expressaram a autonomia do Catalogador, visto que não há uma metodologia efetiva que dê respaldo nesta atividade de indexação nesta instituição.

Foi elaborada em 2010/2011 pela DTRI a primeira versão do Manual para entrada de dados no padrão AACR2 e formato MARC 21, v.1 (livros) e v.2 (teses), contendo instruções de como realizar a catalogação descritiva de livros e dissertações/teses. Entretanto, ressalta-se nos manuais a necessidade de diretrizes para a identificação e seleção de conceitos na indexação de um documento.

\subsubsection{Explicitação dos objetivos da leitura}

Deixar transparecer os objetivos de leitura demonstra que o Catalogador tem consciência da importância em delimitar o assunto do documento e assim determinar conceitos que o representem para que seja possível a recuperação da informação. No entanto, o profissional não menciona nenhuma vez durante a indexação os objetivos para uma leitura profissional.

Fujita (2004) considera a leitura do indexador como uma leitura profissional, uma vez que a leitura neste caso é direcionada com a finalidade profissional de elaboração de uma classificação, para a indexação e para o resumo, objetivos estes muito diferentes da leitura comum.

\subsubsection{Preocupação com o interesse de pesquisa dos usuários}

Apesar da organização da informação e sua disponibilização para o acesso dos documentos serem feitos para uma comunidade usuária, o Catalogador apresenta pouca preocupação com os usuários, mencionando-se apenas uma vez. Além disso, pauta-se mais na linguagem de indexação do que no próprio conteúdo do documento, ou mesmo nas necessidades de busca pelos usuários para a determinação dos conceitos representativos do documento.

Cesarino; Pinto (1985) apontam a importância da identificação das características dos usuários quanto à área de interesse bem como o nível, experiência e atividades que exercem; o volume e a característica tanto da literatura integrada ao sistema quanto das questões propostas pelo usuário e a qualidade dos recursos humanos envolvidos. (Cesarino e Pinto, 1985).

De acordo com Moreiro González (2004), os Catalogadores devem interpretar o documento levando em consideração as necessidades dos usuários, porém inevitavelmente sempre o fará a partir do contexto da cultura a que pertence e suas experiências profissionais. 


\subsubsection{Definição da quantidade de termos na Catalogação de Assunto}

Ao identificar e definir os conceitos, o catalogador, utiliza-se de 4 termos para representar o documento, porém o Manual o auxilia no uso de 5 termos ou mais.

A exaustividade na indexação é um quesito importante para a elaboração de uma política de indexação, visto que o número de termos deve abranger o conteúdo temático por completo. Portanto, quanto mais termos são atribuídos ao documento, mais acessível ele se torna. Por outro lado, a exaustividade por permitir uma maior acessibilidade, acaba por trazer mais documentos que não serão pertinentes para a busca.

No entanto, para a identificação dos conceitos, o catalogador deve-se basear na aplicação de duas regras: Seletividade (só devem ser relacionados os conceitos que representam as informações do documento, suscetíveis de interesse ao usuário) e Exaustividade (todos os conceitos úteis devem ser relacionados) (Van Slype, 1977, apud Chaumier, 1988).

Frequentemente o catalogador será tentado a identificar um ou outro conceito porque aquela palavra ou expressão foi utilizada pelo autor no texto. Ao analista cabe se interrogar se um usuário fizer uma pergunta sobre esse conceito, e se esse documento lhe for fornecido, será pertinente aos olhos daquele usuário? Essa é a questão chave de toda indexação no que concerne à seletividade (Chaumier, 1988).

\subsubsection{Uso e importância de uma política de indexação ou manual}

O Catalogador deixa claro que existe um Manual que foi elaborado para entrada de dados, porém aponta que há necessidade de melhores especificações, pois diz que o manual não apresenta explicações profundas de como identificar os assuntos do documento.

É de grande importância que os sistemas de Bibliotecas, como o da Unicamp, tenham a preocupação em redigir um Manual que se preocupe com as questões de cunho descritivo do material informacional, no entanto, percebe-se que pouca atenção é dada ao processo de descrição e análise de assunto, mais especificamente ao processo de Indexação.

No entanto, vê-se que apesar de existir uma pré-disposição para o uso de uma política de indexação, esta não possui uma atualização frequente e também não possui uma especificidade nos processos de indexação, como deve ser a retirada dos termos, as partes textuais a serem analisadas e a exaustividade na identificação dos conceitos.

Os itens tratados no Manual desta instituição não abrangem a fundo todas as partes do processo de indexação como, por exemplo, a Leitura Documentária, apenas descreve de forma rápida sobre as etapas da indexação e a análise do documento.

Para Carneiro (1985) uma política de indexação, como um guia para tomada de decisões, deve levar em conta os seguintes fatores: a) características e objetivos da organização, determinantes do tipo de serviço a ser oferecido; b) identificação dos usuários, para atendimentos de suas necessidades de informação; c) recursos humanos, materiais e financeiros, que delimitam o funcionamento de um sistema de recuperação da informação.

Portanto, um manual ou política de indexação tem o papel de otimizar os serviços em sistemas de recuperação da informação e sua elaboração e uso tornam-se essenciais para o desenvolvimento e aprimoramento das atividades, inclusive para tomada de decisões.

\subsubsection{Uso de linguagem documentária}

O uso de um vocabulário controlado faz-se necessário na medida em que se torna essencial para a representação e busca da informação (Redigolo, 2010).

No entanto, por esta análise foi possível verificar que o Catalogador baseia-se no próprio sistema da Biblioteca - Base Acervus, Pesqbib (Programa que permite $O$ acesso à linguagem da Rede BIBLIODATA (LCARB) e por vezes no DeCS (Descritores em Ciências da Saúde) para identificar e selecionar os conceitos dos documentos, bem como para verificar se os termos são autorizados.

Infere-se que somente o uso do BIBLIODATA (LCARB) torna-se insatisfatório para a tradução dos conceitos, pois o catalogador passa a utilizar termos não autorizados do DeCs, demonstrando a falta de representatividade que a LCARB possui no processo de indexação que refletirá na busca da informação por assunto.

Neste contexto, ressalta-se que as linguagens documentárias, para Cintra (2002), têm o objetivo de assegurar a organização e a transferência da informação.

Sendo assim, para o desenvolvimento de uma política de indexação, é necessário que os profissionais tenham acesso ao uso de um vocabulário controlado, para que a linguagem de co- 
municação entre o sistema de organização da informação e a linguagem dos usuários seja compatível.

Porém, faz-se necessário que o catalogador identifique previamente conceitos contidos nos documentos, por meio da leitura documentária, pois para Moura, Silva e Amorim (2002), as linguagens documentárias devem ser vistas como auxiliares na atividade de representação e recuperação da informação, e atuam nos sistemas de informação orientando o indexador sobre quais os melhores termos para a representação do assunto de um documento e os pesquisadores na elaboração das estratégias de busca de informações.

\subsubsection{Atualização dos termos inseridos na base Acervus}

A questão do Grupo de Qualidade apresentado pelo Catalogador refere-se a uma equipe de bibliotecários responsável pela correção e qualidade dos dados inseridos na base Acervus. No entanto, se os Catalogadores não estiverem preparados para alimentar essa base e fazer uma análise de assunto condizente com a realidade da Biblioteca, o trabalho do Grupo de Qualidade ficará comprometido.

Constatou-se, com a análise, a importância da atualização dos termos inseridos na base Acervus e a preocupação da equipe técnica em relação à atualização desses termos, mostrando-se assim a importância de uma política que norteie as decisões, e que dê diretrizes para a indexação, considerando-se ainda a importância de atualização do profissional catalogador.

Portanto, infere-se que uma política de indexação deve prever também esta atualização, pois as áreas de conhecimento inovam, os termos mudam e surgem outros, nada é estático. Além disso, não haverá uma padronização se o processo de análise de assunto não estiver estipulado na política de indexação.

Na primeira categoria, Exame do documento de acordo com a norma 12.676 (ABNT, 1992) e alocamento de atenção a áreas importantes (Brown, 1980) observa-se que o sujeito participante da coleta de dados compreende a importância de se analisar partes do documento. Percebe que deve se ater às partes para identificar os conceitos, porém, o Manual para entrada de dados traz apenas alguns itens que podem ser observados. Uma forma de melhor explicitar tais pontos seria consultar a Norma 12.676 (ABNT, 1992).

Além disso, deveria explicar mais precisamente as partes do documento que podem ser consul- tadas na Leitura Documentária do profissional para indexação do material.

As outras categorias encontradas na análise do protocolo também são de suma importância para serem incluídas em uma política de Indexação. Ao realizar a Leitura Documentária, ou como é descrito no Manual para entrada de dados (...) leitura técnica, o profissional Catalogador/Indexador deve levar em consideração: explicitação dos objetivos da leitura (Brown, 1980); preocupação com o interesse de pesquisa dos usuários; e definição da quantidade de termos na catalogação de assunto.

Na própria fala do sujeito da pesquisa, observase a relevância de se ter uma política de Indexação. Essa inclusive também foi uma categoria estabelecida pela análise do Protocolo Verbal, sendo: Uso e importância de uma política de indexação / manual.

\subsection{Avaliações: extrínseca mediante} a interconsistência e a intrínseca quantitativa

Para a avaliação da catalogação de assunto, utilizou-se a fórmula de Hooper (1965), adaptada por Gil Leiva (2008), com o intuito de comparar a consistência dos resultados da catalogação original de um mesmo livro em seis catálogos coletivos on-line de sistemas de recuperação da informação): Library of Congress (LC), Pontifícia Universidade Católica de Campinas (PUC Campinas), Universidade Federal de São Carlos (UFSCar), Universidade Estadual Paulista (UNESP), Universidade Estadual de Campinas (UNICAMP) e Universidade de São Paulo (USP).

A análise das catalogações do mesmo livro nos seis catálogos distintos permitiu não somente a análise dos termos de indexação, como também a comparação entre os números de chamada determinado por cada biblioteca. Os resultados apontam que, em relação ao número de chamada, a notação 615.836 refere-se à Aero terapêutica, segundo a Classificação Decimal de Dewey, $18^{\circ}$ edição. A maioria das Bibliotecas usou a mesma notação e todas utilizaram o assunto Terapia Respiratória na catalogação de assunto, sendo também o primeiro a aparecer no campo Marc. No entanto, a USP utilizou a notação da NLM Classification (Classificação da Biblioteca Nacional de Medicina dos Estados Unidos). O número de chamada WB342 corresponde ao tópico Inalatória / Intranasal, em Administração de medicamentos.

O delineamento dos resultados apresenta-se no Quadro I. 


\begin{tabular}{|c|c|c|c|c|c|c|}
\hline & LC & PUC Campinas & UFSCar & UNESP & UNICAMP & USP \\
\hline Assunto 1 & $\begin{array}{c}\text { Terapia } \\
\text { respiratória }\end{array}$ & $\begin{array}{c}\text { Terapia } \\
\text { respiratória }\end{array}$ & $\begin{array}{c}\text { Terapia } \\
\text { respiratória }\end{array}$ & $\begin{array}{c}\text { Terapia } \\
\text { respiratória }\end{array}$ & $\begin{array}{c}\text { Terapia } \\
\text { respiratória }\end{array}$ & $\begin{array}{c}\text { Terapia } \\
\text { respiratória }\end{array}$ \\
\hline Assunto 2 & & $\begin{array}{l}\text { Exercícios } \\
\text { respiratórios - Uso } \\
\text { terapêutico }\end{array}$ & & $\begin{array}{l}\text { Exercícios } \\
\text { respiratórios - Uso } \\
\text { terapéutico }\end{array}$ & & \\
\hline Assunto 3 & & Fisioterapia & & & & \\
\hline Assunto 4 & & & $\begin{array}{l}\text { Tratamento } \\
\text { respiratório }\end{array}$ & & & \\
\hline Assunto 5 & & & & & $\begin{array}{l}\text { Aparelho } \\
\text { respiratório - } \\
\text { Anatomia }\end{array}$ & \\
\hline Assunto 6 & & & & & $\begin{array}{l}\text { Aparelho } \\
\text { respiratório - } \\
\text { Fisiologia }\end{array}$ & \\
\hline Assunto 7 & & & & & $\begin{array}{l}\text { Aparelho } \\
\text { respiratório - } \\
\text { Doenças }\end{array}$ & \\
\hline $\mathrm{N}^{\circ}$ chamada & 615.836 & 615.836 & 615.836 & 615.836 & 615.836 & WB342 \\
\hline
\end{tabular}

Quadro I. Levantamento dos assuntos catalogados do mesmo documento nos catálogos coletivos on-line de Bibliotecas universitárias

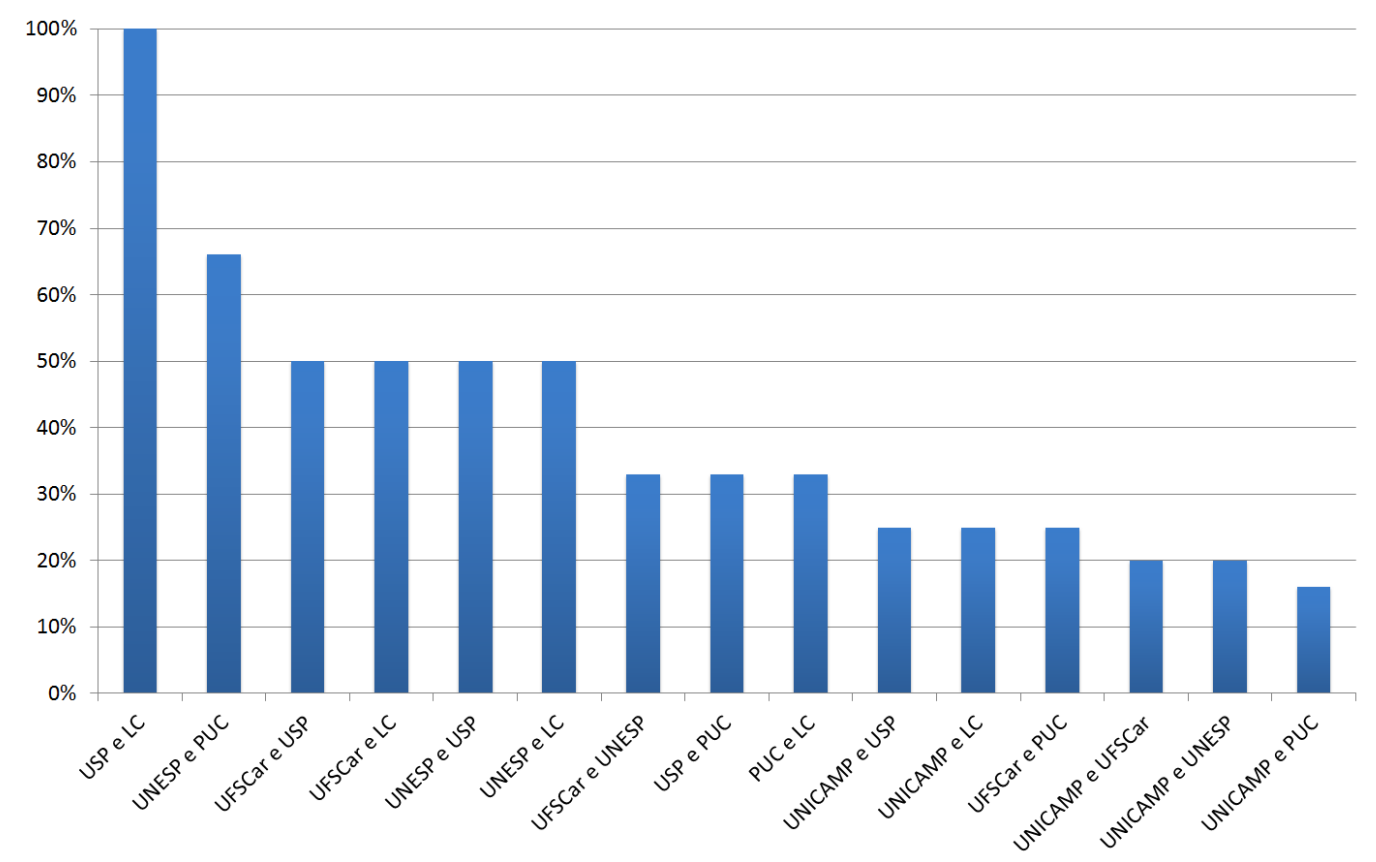

Gráfico 1. Comparação do índice de consistência dos assuntos indexados do mesmo livro nos sistemas de informação das Bibliotecas Universitárias

A seguir, retoma-se a fórmula da consistência de Hooper (1965) adaptada por Gil Leiva, 2008):

$$
\mathrm{Ci}=\mathrm{Tco} /[(\mathrm{A}+\mathrm{B})-\mathrm{Tco}]
$$

Tco = Número de termos comuns nas duas indexações

$A=$ Número de termos usados na indexação $A$

$B=$ Número de termos usados na indexação $B$

$\mathrm{Ci}=$ Índice de Consistência
Ao aplicarmos a fórmula da consistência entre todas as seis catalogações, obteve-se os seguintes resultados, apresentados no Gráfico 1.

Sendo assim, o maior índice de consistência na indexação do livro foi entre a USP e a LC $(100 \%)$, pois ambas indexaram um único e mesmo assunto para o livro. Por outro lado, o menor índice de consistência ficou entre a Uni- 
camp e a PUC (16\%). Se considerarmos o índice de consistência da indexação apenas da Unicamp em comparação com as demais bibliotecas, teremos o seguinte resultado, demonstrado no Gráfico 2:

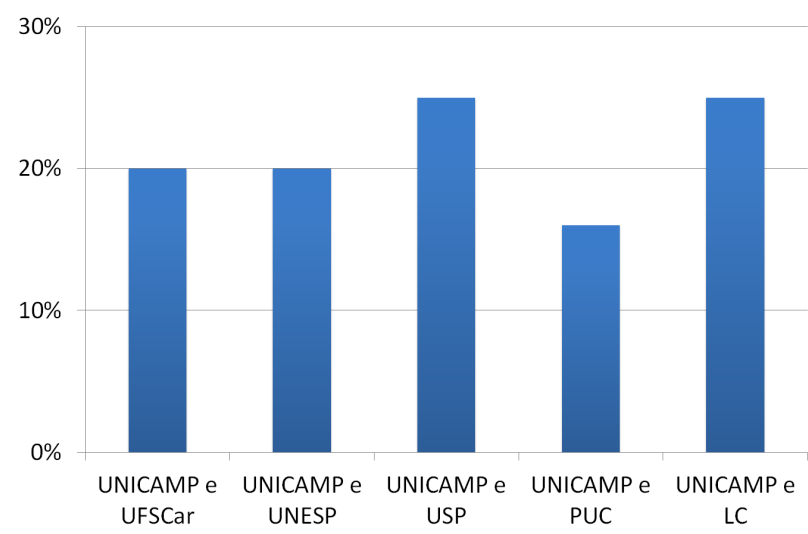

Gráfico 2. Comparação do índice de consistência dos assuntos indexados do mesmo livro na UNICAMP com outras bibliotecas universitárias.

Portanto, o maior índice de consistência na indexação do livro foi entre a Unicamp e a USP (25\%) e entre a Unicamp e a LC (25\%), enquanto que a Unicamp e a PUC (16\%) apresentaram o menor índice de consistência entre a indexação do mesmo livro.

Esclarece-se que apesar da amostra avaliada ser pequena, percebe-se que em ambas as avaliações, o índice de consistência apresentase muito baixo. Gil Leiva (2008, p. 391) descreve que umas das principais razões para esta diversidade na indexação do mesmo documento, na maioria das situações, é o uso de diferentes linguagens documentárias, distintas políticas de indexação que regem casa sistema de informação e a subjetividade inerente ao processo de indexação.

A formação e construção de catálogos online permitem a visibilidade do conteúdo informacional das Bibliotecas Universitárias. Entretanto, a escolha de assunto(s) e sua(s) respectiva(s) entradas no catálogo é permeado pela subjetividade e bom senso profissional, considerando-se que o Catalogador de assunto em geral não é um especialista na área do conhecimento em que atua.

No entanto, ao analisar um documento para a representação em índices, a atitude do Catalogador de assunto está diretamente vinculada com sua concepção de análise adquirida durante a formação educacional e da política de indexação do sistema de recuperação da informação. Consequentemente, tal fator acarreta dís- pares na consistência da catalogação de assunto e prejudica a qualidade dos produtos e serviços informacionais.

Referente ao contexto da Biblioteca da Faculdade de Ciências Médicas da Unicamp esta problemática é ainda maior, uma vez que não existe uma política de indexação formalizada em um Manual de indexação que norteie a catalogação de assunto na base Acervus. Dessa forma, o processo de indexação deverá ser regido por uma política própria e única, que leve em consideração a instituição como um todo, seus usuários, colaboradores, estrutura física e financeira, entre outros. A atividade de indexação não deve ser vista como um mero fazer técnico, mas sim como um processo intelectual, dependente da coleção e da comunidade usuária local.

\section{Considerações finais}

O processo de determinação do assunto de um documento envolve um alto grau de complexidade, pois além da diversidade terminológica dos documentos e da própria área, existe a influência direta dos profissionais que a executam, conhecida como subjetividade, na qual o catalogador interpõe seus próprios valores na sua atuação de intermediário entre autores e usuários. Envolve aspectos lógicos, cognitivos e linguísticos da leitura, entre outros, como a influência da política de indexação e da cultura organizacional do sistema de informação no qual atua.

Quanto ao manual de política de indexação, ressalta-se que deve ser um instrumento real de trabalho e norteador dos princípios do processo de tratamento documentário pela biblioteca universitária, a fim de que seja garantida a consistência na catalogação de assunto, tornandose necessário que a política de indexação esteja descrita de maneira clara e objetiva e ao alcance de todos os atores que contribuem para o desenvolvimento desse processo dentro do sistema de informação - inclusive os próprios usuários.

Acredita-se que a continuidade e o aperfeiçoamento de uma política de indexação no decorrer dos anos dependem, sobretudo, de seu registro em documentos, "[...] de modo que se possa ter clareza do conjunto de decisões tomadas, suas razões e seu contexto" (Guimarães, 2000, p. 5556). Apoiando-se na citação, pode-se afirmar a importância da avaliação da indexação e do conhecimento da cultura organizacional para o aprimoramento dos manuais de indexação, bem como do processo de catalogação de assunto em bibliotecas universitárias. 
O estudo partiu de um levantamento do contexto da organização, por meio da cultura organizacional, pois a política de indexação deve levar em consideração a Instituição por completo, além das necessidades de sua comunidade usuária. Por isso a relevância em se tratar da Cultura Organizacional. Com esta análise constata-se que se trata de uma grande instituição, com uma quantidade considerável de acervo e poucos bibliotecários, sendo que possui um quadro grande de funcionários sem a formação bibliotecária, o que sugere ainda mais a necessidade de um manual de política de indexação.

A aplicação do Protocolo Verbal Individual, por ser um método introspectivo que permitiu não somente a observação da catalogação propriamente dita e como a atividade vem sendo realizada na biblioteca, como também o contexto do trabalho do catalogador, além das facilidades, das dificuldades e muitas vezes, algumas deficiências, como na formação do profissional, na falta de manuseio e leitura do material a ser catalogada, a importação dos registros de catalogação do sistema de cooperação sem adequá-los, e neste contexto de observação a partir da análise do protocolo, foi possível identificar algumas categorias necessárias para a elaboração de uma política que contribua para a melhora dos resultados de indexação, como: indicações de como analisar os documentos, partes textuais mais relevantes, assim como se observa no Modelo de Leitura Documentária para Indexação de artigos científicos, criado por Fujita 2003; Explicitação dos objetivos de leitura; Interesses dos usuários; Definição dos termos de indexação; Uso de uma linguagem documentária atualizada; Atualização dos termos usados no catálogo.

Verifica-se que apenas o uso da linguagem da Rede BIBLIODATA (LCARB) na área Médica torna-se insatisfatório na tradução dos conceitos, utilizando-se o catalogador de termos disponibilizados por outros sistemas de organização do conhecimento como o DeCs, demonstrando a falta de representatividade que a LCARB possui no processo de indexação que refletirá na busca da informação por assunto, como aponta Boccato e Fujita (2010), sendo ela utilizada apenas para a confirmação e validação dos cabeçalhos.

Sugere-se que a linguagem documental seja conhecida pelos usuários, otimizando a busca por assunto nos catálogos online e que se construa um vocabulário controlado específico da Unicamp, considerando-se o perfil acadêmico que a universidade e a própria base Acervus possuem, aumentando a credibilidade da representatividade e a visibilidade desta biblioteca.
A investigação buscou ainda oferecer estudo de elementos para discussões de uma política de indexação sobre a perspectiva profissional. No entanto, como este trabalho investigou uma amostra da catalogação de assunto realizada por um catalogador no contexto específico da Biblioteca da Faculdade de Ciências Médicas da Unicamp (BFCM), faz-se necessário mais estudos com os catalogadores da área, com a participação de especialistas, usuários e dirigentes para a elaboração de um manual específico de política de indexação da área Médica.

Esclarece-se ainda, que a avaliação da indexação, quando realizada com uma amostra suficientemente grande, possibilita obter um feedback da representação da informação, deve-se levar em consideração também que sempre existirá variação entre as indexações, pois é uma atividade mais subjetiva do que objetiva. $\mathrm{O}$ baixo índice de consistência dos assuntos indexados do mesmo livro entre as seis bibliotecas universitárias brasileiras pesquisadas reforça a importância do estabelecimento da política de indexação em cada contexto, considerando-se também as especificidades de cada comunidade acadêmica.

Este mesmo cenário pode ser encontrado em países europeus, como por exemplo, a Espanha, que além de sofrer pela carência de linguagens controladas atualizadas, também faltam Políticas de Indexação efetivas que determinem esse processo, pois assim como no Brasil, existe uma tendência em focar o tratamento de artigos científicos em base de dados, enquanto a catalogação de livros em bibliotecas segue sem maiores reflexões. As vantagens de aplicação desta metodologia de avaliação da indexação e também o uso de políticas de indexação, concentra-se na busca por uma consistência dos resultados da indexação, que serão refletidos na recuperação e uso da informação. Deste modo, aponta-se ainda a necessidade de mais investigações voltadas para o profissional que realiza o tratamento temático da informação em Bibliotecas universitária, para que as etapas do processo de catalogação de assunto possam ser padronizadas, visando diminuir/eliminar incoerências ou omissões e dar maior consistência para a criação de produtos informacionais.

\section{Agradecimentos}

Ao profissional que participou da coleta de dados e contribuiu para os objetivos desta pesquisa.

\section{Referências}

Associação Brasileira de Normas Técnicas (1992). NBR 12676: Métodos para análise de documentos - determi- 
nação de seus assuntos e seleção de termos de Indexação. Rio de Janeiro: ABNT. 4 p.

Boccato, V. R. C.; Fujita, M. S. L. (2005). Avaliação de linguagem documentária na perspectiva da Cultura Organizacional do Sistema de Informação BIREME com enfoque no desenvolvimento da ciência brasileira. // 9th International Congress Medical Librarianship - ICML9; 7th Latin American and Caribbean Congress on Health Sciences Information - CRICS VII, 2005, Salvador, 2005.

Boccato, V. R. C; Fujita, M. S. L. (2010). O uso de linguagem documentária em catálogos coletivos de bibliotecas universitárias: um estudo de avaliação sociocognitiva com protocolo verbal. // Perspectivas Ciência da informação. 15:3, 23-51. http://www.scielo.br/scielo.php? script=sci_arttext\&pid=S1413-99362010000300003\&lng $=$ pt\&nrm=iso $(04-03-2011)$.

Borba, E. A. (2003). Leitura para Indexação: o uso da Linguagem Documentária como estratégia específica do leitor profissional. Trabalho de Conclusão de Curso (Graduação em Biblioteconomia)-Faculdade de Filosofia e Ciências, Universidade Estadual Paulista, Marília, 2003. $65 \mathrm{f}$.

Brown, N. (1980). Metacognitive development and reading. // SPIRO et al. (orgs). Theorical issues in reading comprehension. New Jersey: L. Erlbaum Associate Publisers, 1980.

Carneiro, M. V. (1985). Diretrizes para uma política de indexação. // Revista da Escola de Biblioteconomia da UFMG, Belo Horizonte. 14:2 (set. 1985) 221-241.

Cesarino, M. A. N.; Pinto, M. C. M. (1978). Cabeçalho de assunto como linguagem de Indexação. // Revista da Escola de Biblioteconomia da UFMG, Belo Horizonte. 7:2 (set. 1978) 268-288.

Cintra, A. M. M. et al. (2002). Para entender as linguagens documentárias. 2. ed. rev. e atual. São Paulo: Editora Polis.

Chaumier, J. (1988). Indexação, conceito, etapas e instrumentos. // Revista Brasileira de Biblioteconomia e Documentação. 21:1-2, 63-79, 1988.

Dal' evedove, R. C. (2002). Compreensão de leitura em Análise de assunto para identificação e seleção de conceitos. Trabalho de Conclusão de Curso. (Graduação em Biblioteconomia) - Faculdade de Filosofia e Ciências, Universidade Estadual Paulista, Marília. $154 \mathrm{f}$.

Dias, E. W.; Naves, M. M. L. (2007). Análise de assunto: teoria e prática. Brasília: Thesaurus, 2007. $116 \mathrm{p}$.

Fujita, M. S. L. (2001). Leitura em análise documentária: uma contribuição à formação do indexador. Marília: UNESP; CNPq, 2001. 190 p. (Relatório parcial de pesquisa).

Fujita, M. S. L. (2003a). A identificação de conceitos no processo de análise de assunto para indexação. // Revista Digital de Biblioteconomia e Ciência da Informação, Campinas.1:1, jul. 2003a. http://bibli. fae.unicamp.br/revbib/index.html (11-04- 2006).

Fujita, M. S. L. (2004). A leitura documentaria na perspectiva de suas variáveis: leitor-texto-contexto. // DataGramaZero: Revista de Ciência da Informação.5:4 (ago. 2004). http://dici.ibict.br/archive/00000350/01/A leitura document\%C3\%A1ria_na_perspectiva_de_suas_vari\% C3\%A1veis.pdf (13-03-2006).

Fujita, M. S. L.; Rubi, M.P. (2007). Metodologia sociocognitiva para coleta de dados e recurso pedagógico em sala de aula. // Labegalini, A. C. F. B. (Org.). Pesquisa em educação: passo a passo. Marília: Edições M3T.

Gil Leiva, I. (2002). Consistencia en la indización de documentos entre indizadores noveles. // Anales de documentación. 5, 99-111.http://www.um.es/fccd/anales/ ad05/ad0505.pdf (11-10- 2002).
Gil Leiva, I. (2008). Manual de indización: teoria y práctica. España: Ediciones TREA, S.L.

Guimarães, J. A. C. (2000). Políticas de análisis y representación de contenido para la gestión del conocimiento en las organizaciones. // Scire. 6:2 (jul./dic. 2000) 48-58.

Guimarães, J. A. C. (2004). As políticas de indexação como elemento para a gestão do conhecimento nas organizações. // Vidotti, S. A. G. (coord.). (2004). Tecnologia e conteúdos informacionais: abordagens teóricas e práticas. São Paulo: Polis. 43-52.

Kobashi, N. (1994). A elaboração de informações documentárias: em busca de uma metodologia. Tese (Doutorado em Ciências da Comunicação) - Escola de Comunicações e Artes, Universidade de São Paulo, São Paulo.

Lancaster, F. W. (1991). Indexing and abstracting in Theory and Practice. London: Library Association.

Lancaster, F. W. (2004). Indexação e resumos: teoria e prática. 2. ed. Brasília: Briquet de Lemos.

Moreno Fernández, Luis Miguel (2003). La consistencia de la indización: I. Precisiones conceptuales, medidas, usos en los procesos documentales y relación entre coherencia e indización. // AIBDA. Costa Rica. 24:1-2 (jan-dec. 2003) 1-30.

Moreiro González, J. A. (2004). El contenido de los documentos textuales: su análisis y representación mediante el lenguaje natural. España: Ediciones TREA, S.L.

Moura, M. A.; Silva, A. P.; Amorim, V. R. de (2002). A concepção e o uso das linguagens de indexação face às contribuições da semiótica e da semiologia. // Informação e Sociedade: Estudos. João Pessoa. 12:1 (jan./jun. 2002). http://www.ies.ufpb.br/ojs2/index.php/ ies/article/viewFile/160/154 (15-08- 2007).

Naves, M.M.L. (1996). Análise de assunto: concepções. // Revista de Biblioteconomia de Brasília. 20:2 (jul./dez, 1996) $215-226$.

Nunes, C. O. (2004). Algumas considerações acerca da ausência de políticas de indexação em bibliotecas brasileiras. // Biblos. Rio Grande do Sul. 16, 55-61.

Redigolo, F.M. (2010). O processo de análise de assunto na catalogação de documentos: a perspectiva sociocognitiva do catalogador em contexto de biblioteca universitária. Dissertação (Mestrado em Ciência da Informação) Faculdade de Filosofia e Ciências, Universidade Estadual Paulista, Marília.

Rubi, M. P. (2004). A política de indexação na perspectiva do conhecimento organizacional. Dissertação (Mestrado em Ciência da Informação). Marília: Faculdade de Filosofia e Ciências, Universidade Estadual Paulista. 135 f.

Rubi, M. P. (2008). Política de indexação para construção de catálogos coletivos em bibliotecas universitárias. 2008. 166. Tese (Doutorado em Ciência da Informação). Marília: Faculdade de Filosofia e Ciências, Universidade Estadual Paulista,

Sistema de Bibliotecas da Unicamp. (2011). http://www.unicamp.br/unicamp/servicos/Bibliotecas (2308- 2011).

Universidade Estadual de Campinas, Sistema de Bibliotecas da UNICAMP, Diretoria do Tratamento da Informação (2010). Manual para entrada de dados no padrão AACR2 e formato MARC 21: 1 Monografias: Livros (Versão 1). Campinas: Diretoria do Tratamento da Informação.

Van Slype, Georges. (1977). Conception et gestion des systemes documentaries. Paris: Ed. d'Organisation.

Enviado: 2012-04-28. Versión corregida: 2012-06-05. Aceptado: 2012-07-01. 